\title{
Morfealı hastalarda klinik özellikler, laboratuvar bulguları, seçilen tedavi yöntemi ve takip sonuçları
}

\author{
The clinical features, laboratory findings, treatment and follow-up \\ results of patients with morphea
}

\author{
Nehir Parlak, Bengü Nisa Akay*, Hatice Erdi Șanlı*, Aynur Akyol* \\ Prof. Dr. Celal Ertuğ Etimesgut Devlet Hastanesi, Deri ve Zührevi Hastalıklar Kliniği, Ankara, Türkiye \\ *Ankara Üniversitesi Tıp Fakültesi, Deri ve Zührevi Hastalıklar Anabilim Dalı, Ankara, Türkiye
}

\section{Özet}

Amaç: Morfea lokalize skleroderma olarak da bilinen, deri ve deri altı dokuda fibrozis ile karakterli, patogenezi bilinmeyen nadir bir deri hastalığıdır. Bu çalışmada, morfea tanısı alan olgularda, demografik özellikler, klinik seyir, laboratuvar bulguları ve tedavi yanıtlarının değerlendirilmesi amaçlanmıştır.

Gereç ve Yöntem: Çalışma 1995-2011 yılları arasında morfea tanısı konulan 58 hastanın retrospektif olarak incelenmesiyle gerçekleştirilmiştir. Tüm hastaların klinik bulguları, eşlik eden hastalıkları, semptomları, immünolojik antikor profilleri, periferal eozinofili varlığı ve tedavi yanıtları araştııımıştır. 2-12 ay süre ile tedavisi devam etmiş olan 40 hastanın tedavi yöntemleri ve tedaviye yanıtları incelenmiştir.

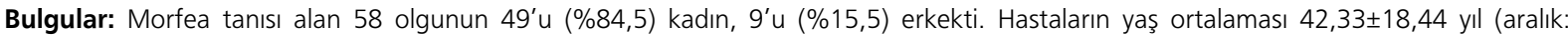
7-75yıl) idi. Olguların tamamına morfea tanısı histopatolojik inceleme ile konulurken, borrelia antikorları negatif olarak saptandı. Lezyonlar 36 olguda $(\% 62,1)$ plak tip, 17'sinde $(\% 29,3)$ generalize tip, 3'ünde $(\% 5,2)$ miks (lineer + plak) tip, 2'sinde $(\% 3,4)$ lineer tip morfea olarak sınıflandııılı. ANA seviyesi 46 olgunun 12 'sinde $(\% 26,2)$ pozitif olarak bulundu. Morfeanın klinik tipleri ile ANA arasındaki ilişki incelendiğinde plak tipi olanların \%38,5'inde, generalize tipi olanların \%53,8'inde, miks tip morfealı olguların \%7,7'sinde ANA pozitifliği saptanmıştı. Generalize morfeası olan hastalarda ANA pozitifliğinin anlamlı olduğu görüldü ( $p=0,027)$. Anti ds-DNA 1 olguda (\%2,7), antihiston antikor 1 olguda $(\% 1,7)$ ve anti-ku antikor 3 olguda $(\% 8,6)$ pozitif olarak saptandı. Periferal eozinofili 1 olguda $(\% 2,1)$ mevcuttu ve bu olguda lezyonlar generalize idi. Olguların 23'üne kolşisin tedavisi verildiği görüldü. Kolşisin tedavisi kullanan hastaların \%47,8'inde tedaviye komplet yanıt, \%26,1'inde parsiyel yanıt alınırken, \%17,4'ünde hastalık stabil kalmış, \%8,7'sinde ise progresyon izlenmiştir.

Sonuç: Çalışmamızın sonucunda plak tip morfeanın diğer tiplere oranla daha sık görüldüğü, generalize tip morfeada ise ANA pozitifliğinin anlamlı olduğu saptanmışır. Kolşisinin tedavide etkili ve güvenilir olduğu ve yeni lezyon çıkışını durdurduğu gözlenmiştir. (Türkderm 2013; 47: 209-13)

Anahtar Kelimeler: Otoaantikorlar, kolşisin, lokalize skleroderma, morfea

\section{Summary}

Background and Design: Morphea, also known as localized scleroderma, is a rare skin disease of unknown pathogenesis, characterized by fibrosis of the skin and subcutaneous tissue. In this study, we aimed to evaluate the demographic features, clinical characteristics, laboratory findings, and response to treatment in patients diagnosed with morphea.

Materials and Methods: We retrospectively evaluated medical records of fifty-eight patients diagnosed with morphea between 1995 and 2011. Clinical symptoms, concomitant diseases, symptoms, immunological features and presence of peripheral eosinophilia were investigated. Treatment methods and response to therapy in 40 patients whose treatment continued for 2-12 months were examined.

Results: Forty-nine patients (84.5\%) were female and 9 (15.5\%) were male. The mean age of the patients was $42.33 \pm 18.44$ years (range: 7-75 years). The diagnosis was made by histopathological examinations in all cases. Borrelia antibodies were negative in all patients. Thirtysix patients $(62.1 \%)$ had plaque type, 17 patients $(29.3 \%)$ had generalized type, 3 patients $(5.2 \%)$ had mixed type (linear + plaque) and 2 patients (3.4\%) had linear type morphea. Antinuclear antibody (ANA) was found to be positive in $12(26.2 \%)$ of 46 patients. Considering the

Yazışma Adresi/Address for Correspondence: Dr. Nehir Parlak, Prof. Dr. Celal Ertuğ Etimesgut Devlet Hastanesi, Deri ve Zührevi Hastallklar Kliniği, Ankara, Türkiye Tel.: +90 3122933000 E-posta: nehirkucukuslu@hotmail.com Geliş Tarihi/Received: 19.01.2013 Kabul Tarihi/Accepted: 11.03.2013 
relationship between the clinical types of morphea and ANA, 38.5\% of plaque type, 53.8\% of generalized type, $7.7 \%$ of mixed type patients showed ANA positivity. ANA positivity was statistically significant in patients with generalized morphea $(p=0.027)$. Peripheral eosinophilia was detected in one patient in whom the lesions were generalized (2.1\%). Colchicine therapy was given to 23 cases. Complete and partial response rates were $47.8 \%$ and $26.1 \%$, respectively. However, $17.4 \%$ of patients remained stable and progression was noted in $8.7 \%$ of the cases.

Conclusion: In conclusion, plaque type morphea is the most common type of morphea. ANA positivity was statistically significant in patients with generalized skin lesions. Colchicine is an effective and safe treatment option. (Turkderm 2013; 47: 209-13)

Key Words: Autoantibodies, colchicine, localized scleroderma, morphea

\section{Giriş}

Morfea, lokalize skleroderma olarak da bilinen deri ve subkutan dokuda fibrozis ile karakterli patogenezi tam olarak anlaşılamamış bir hastalıktır. Sistemik sklerozdan, sistemik tutulum dışında Raynoud fenomeni, skerodaktili ve periungual kapiller değişikliklerin olmayışı ile ayrılmaktadır. Travma, radyasyon, ilaçlar, infeksiyonlar, otoimmünite ve mikrokimerizm gibi multifaktöryel etkenler morfea gelişimine neden olabilmektedir ${ }^{1}$. Nadir ve kadınlarda daha sık görülen hastalığın insidansı yüzbinde 0,4 ile 2,7 arasındadır2,3.

Hastalık deriyi tutan küçük plaklarla karakterli olabileceği gibi önemli fonksiyonel ve kozmetik sorunlara da neden olabilmektedir. Inflamatuvar dönemde eritemli mor yama ve plaklar vardır. Zamanla plakların ortasında beyaz ve sklerotik bir merkez oluşmakta, ortası fildişi renginde sklererotik, etrafı viole halo ile çevrili morfea plakları gelişmektedir. Aktif faz sona erdiğinde merkezden postinflamatuvar hiperpigmentasyon bırakarak iyileşmektedir.

Pasini Pierini atrofoderması, eozinofilik fasiit ve liken sklerozis et atrofikus gibi hastalıklar morfea alt tipleri arasında yer alırken, sınıflandırmada miks tipin yer almaması yıllar içerisinde yeni sınıflandırmalara gereksinim duyulmasına neden olmuştur 4 . En yeni ve kabul gören sınıflandırma Laxer ve ark.'ları tarafından yapılmış olanıdır. Laxer ve ark.'ları morfeayı plak, generalize, lineer, pansklerotik ve miks tip olmak üzere 5 grupta toplamıştır 5 .

Tüm dünyada morfea ile ilgili değişik çalışmalar yapılmış olmasına rağmen, ülkemizde morfealı çocukların değerlendirildiği ve 2011 yılında yayınlanan bir makale dışında, özellikle erişkin hastaların değerlendirildiği bir çalışma yakın tarihe kadar bulunmamaktadır 6 . Bu çalışmada morfea tanısı olan hastaların demografik özellikleri, laboratuvar bulguları, klinik seyirleri ve farklı tedavi protokollerine vermiş oldukları yanıtların değerlendirilmesi amaçlanmıştır.

\section{Gereç ve Yöntem}

Çalışma 1995-2011 yılları arasında takip edilmiş olan, klinik ve histopatolojik olarak morfea tanısı almış 58 hastanın verilerinin retrospektif olarak incelenmesiyle gerçekleştirilmiştir. Fizik muayene bulguları, yaş, cinsiyet, lezyonların lokalizasyonları, hastalık sınıflandırması, immünolojik laboratuvar bulguları, borrelia antikorları, eozinofili varlığı, seçilen tedavi yöntemleri ve tedaviye yanıt araştırılmıştır. Hastalardan elde edilen ANA, anti ds-DNA, anti-histon, anti-ku antikorları ve eozinofili varlığı ile morfea tipleri arasındaki ilişki ayrıca değerlendirilmiştir. Hastalığa eşlik edebilecek ek hastalıkların varlığı da araştırılmıştır.

Hastalık alt tipleri lokalize (plak), generalize, lineer, pansklerotik ve miks tip olarak sınıflandırımıştır5. Bir ya da birkaç tane, oval veya yuvarlak görünümde, en fazla 2 anatomik bölgede (baş-boyun, her bir ekstremite, ön ve arka gövde) yerleşen plaklar lokalize tip morfea; her biri 3 cm'den büyük, 4 veya daha fazla infiltre plağın izlendiği en az 2 anatomik bölgenin tutulduğu tip generalize morfea; lineer bantlaşmalar gösteren sklerotik lezyonlar (ekstremite tip ve baş bölgesini etkileyen en coup de sabre, Parry-Romberg varyantları) lineer tip; deri ve konnektif dokunun derin tabakaların tutulduğu (yağ dokusu, fasya, kas dokusu gibi) tip pansklerotik morfea olarak kabul edildi.

Komplet yanıt hastalıkta tam düzelme, parsiyel yanıt başlangıç hastalıkta $\% 50$ veya daha fazla düzelme, hastalık progresyonu başlangıç hastalıkta \%25'den fazla artış olarak değerlendirildi. Stabil hastalık ise komplet, parsiyel yanıt ve hastalık progresyonunu karşılamayan kriterlere uyan hastalık olarak değerlendirildi.

Hastalardan elde edilen veriler SPSS 16.0 paket istatistik programına aktarılarak analiz edilmiştir. Veriler ortalama sstandart sapma, yüzde, sayı olarak belirtilmiştir. Kategorik verilerin karşılaştııılmasında ki-kare testi kullanılmış olup $p$ değerinin $<0,05$ olması anlamlı olarak kabul edilmiştir.

\section{Bulgular}

Çalışmaya dahil edilen 58 olgunun 49'u (\%84,5) kadın, 9'u (\%15,5) erkekti. Yaş 7-75 yıl arasında değişmekte iken, yaş ortalaması $42,33 \pm 18,44$ yıl olarak belirlendi. Olguların $8^{\prime} i$; 18 ve 18 yaş altı, $45^{\prime} i$; $18-65$ yaş aralığında, 5'i; 65 ve 65 yaş üzerindeydi. Olguların tamamında tanı histopatolojik inceleme ile doğrulanmıştı ve borrelia antikorları negatifti. Bir olguda hastalık öncesi travma öyküsü mevcuttu.

Plak tip lezyonlar diğer tiplerle karşılaştıııldığında görülme sıklığı istatistiksel olarak anlamlı bulundu $(p<0,001$, Tablo 1). Lezyonlar olguların \%52,7'sinde sadece gövdede veya gövde ile birlikte alt ve/ veya üst ektremitede, \%10,4'ünde baş boyunda, \%37,9'unda üst ekstremite ve/veya alt ekstremite yerleşmekteydi. Çalışmamızda plak tipin bir varyantı büllöz ve pansklerotik morfea tiplerine rastlanmamış olup, plak tip morfealı bir hastada gözlenen nüks periyodunda lezyonlar $1 \mathrm{~cm}$ 'den küçük lezyonların olduğu plak tipin bir varyantı olan guttat morfea şeklinde ortaya çıkmıştı. Lineer morfealı bir olgu "en coup de sabre"şeklinde prezente olmuştu.

ANA değerleri 46 hastanın \%73,9'unda negatif, \%26,1' inde ise pozitif olarak saptandı. Morfea tiplerine göre ANA dağılımları Tablo 1'de gösterilmiştir. Generalize morfealı olgularda ANA pozitifliği diğer morfea tipleriyle karşılaştırıldığında istatistiksel olarak anlamlı bulunmuştur ( $p=0,027$, Tablo 1).

Anti ds-DNA antikorları 37 olgunun 1 'inde $(\% 2,7)$ yüksek saptanırken, anti-histon antikorları 32 olgunun 1'inde $(\% 3,1)$, anti-ku antikorları 35 olgunun 3 'ünde $(\% 8,6)$ pozitif olarak bulundu. Periferal eozinofili 47 olgunun sadece 1 tanesinde $(\% 2,1)$ saptandı.

Hastalarda tedavi seçimi klinik alt tiplere göre yapılmıştır. Tedavide kolşisin, dar bant UVB, metotreksat ve topikal kortikosteroidler tercih edilmiş ve tedavi yanıtları Tablo 2'de gösterilmiştir. Olguların 23 tanesine kolşisinin 1,5 gr/gün dozunda ortalama 6 ay verildiği, tedavi altında progresyon gözlenen olguların tamamının generalize tip, komplet yanıt gözlenen olguların \%66,5'inin ise plak tip morfea olduğu gözlenmiştir. Dar bant UVB tedavisi haftada 3 gün ortalama 60 seans verilmiş, komplet yanıt alınan olgulardan bir tanesinin daha önce kolşisin tedavisine parsiyel 
Tablo 1. Morfea tiplerinin görülme sıklığı, tiplere göre ANA pozitifliklerinin karşılaştırılması ve demografik özellikler

\begin{tabular}{|c|c|c|c|c|c|c|}
\hline & $\begin{array}{l}\text { Görülme sıklığı } \\
(\%,(n))\end{array}$ & $\begin{array}{l}\text { ANA pozitifliği } \\
(\%,(n))\end{array}$ & $\begin{array}{l}<18 \text { yaş olgu } \\
\text { sayısı }(\%,(n))\end{array}$ & $\begin{array}{l}18-65 \text { olgu } \\
\text { sayısı }(\%,(n))\end{array}$ & $\begin{array}{l}>65 \text { olgu } \\
\text { sayısı }(\%,(n))\end{array}$ & $\begin{array}{l}\text { Hastalık } \\
\text { süresi }\end{array}$ \\
\hline Plak tip & $\% 62,1(36)$ & $\% 37,9(22)$ & $\% 87,5(7)$ & $\% 60(27)$ & $\% 40(2)$ & $35 \pm 41$ \\
\hline Miks tip & $\% 5,2(3)$ & $\% 8,7(5)$ & $\% 12,5(1)$ & $\% 4,4(2)$ & - & $30 \pm 21$ \\
\hline Lineer tip & $\% 3,4(2)$ & - & - & $\% 4,4(2)$ & - & $23 \pm 35$ \\
\hline
\end{tabular}

*ki-kare test, Veriler yüzde ve sayı olarak sunulmuştur.

\section{Tablo 2. Morfealı hastalarda kolşisin ile gözlenen tedavi yanıtı}

\begin{tabular}{|c|c|c|c|c|}
\hline Tedavi yanıtı & $\begin{array}{l}\text { Kolşisin } \\
\text { (\%, toplam n, n) }\end{array}$ & $\begin{array}{l}\text { Metotreksat } \\
\text { (toplam n, n) }\end{array}$ & $\begin{array}{l}\text { DB UVB } \\
\text { (toplam n, n) }\end{array}$ & $\begin{array}{l}\text { Topikal steroid } \\
\text { (toplam n, n) }\end{array}$ \\
\hline Komplet & $\begin{array}{l}\% 47,8, \mathrm{n}: 11 \\
7 \text { (plak tip) } \\
4 \text { (generalize tip) }\end{array}$ & $\begin{array}{l}\text { n:5 } \\
3 \text { (generalize tip ) } \\
1 \text { (miks tip) } \\
1 \text { (lineer tip) }\end{array}$ & $\begin{array}{l}\text { n:3 } \\
3 \text { (generalize tip) }\end{array}$ & $\begin{array}{l}\text { n:6 } \\
6 \text { (plak tip) }\end{array}$ \\
\hline Parsiyel & $\begin{array}{l}\% 26,1, \mathrm{n}: 6 \\
2 \text { (generalize) } \\
4 \text { (plak) }\end{array}$ & $\begin{array}{l}\mathrm{n}: 3 \\
3 \text { (generalize tip) }\end{array}$ & - & $\begin{array}{l}\mathrm{n}: 1 \\
1 \text { (plak tip) }\end{array}$ \\
\hline Stabil hastalık & $\begin{array}{l}\% 17,4, \text { n:4 } \\
4 \text { (plak tip) }\end{array}$ & - & $\begin{array}{l}\text { n:1 } \\
1 \text { (generalize tip ) }\end{array}$ & - \\
\hline Progresyon & $\begin{array}{l}\% 8,7, n: 2 \\
2 \text { (generalize tip) }\end{array}$ & - & - & - \\
\hline
\end{tabular}

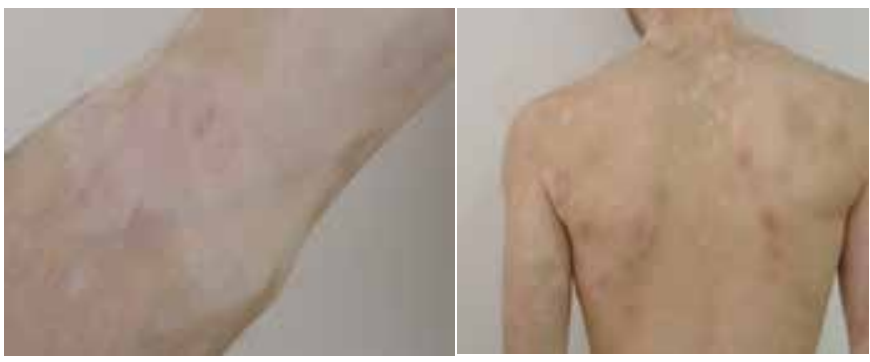

Resim 1. Generalize morfea ve vitiligo birlikteliği

yanıt verdiği gözlenmiştir. Sekiz hastaya ise $0,2 \mathrm{gr} / \mathrm{kg} / \mathrm{hafta}$ dozunda 6-12 ay arasında değişen sürelerde metotreksat tedavisi verilmiş, 5 hastada komplet yanıt, 3 hastada parsiyel yanıt elde edilmiştir. En coup de sabre tipi lineer morfeası olan bir olguya 1yıl süreyle metotreksat ve UVA1 tedavisi kombine olarak verilmiş ve komplet yanıt elde edilmiştir. Topikal steroidler daha çok sınırlı hastalıkta tercih edilmiştir.

Generalize morfealı bir olguda anti Scl 70 antikoru pozitif saptanmasına rağmen yapılan tetkiklerde sistemik tutulum olmadığı ve metotreksat tedavisi ile tedaviye komplet yanıt alındığı ve takiplerde anti Scl 70 antikorunun kaybolduğu gözlenmiştir. Periferal eozinofili, generalize morfeası bulunan bir olguda saptanırken (eozinofili düzeyi: \%20,9), metotreksat tedavisine parsiyel yanıt veren bu olgunun, tedavi sonrası eozinofil değerleri normal sınırlara döndüğü izlenmiştir.

Generalize morfealı bir olguda kolşisin ve topikal steroid kullanımı ile tedaviye komplet yanıt alındıktan sonra yapılan takiplerde eritema diskronikum perstans geliştiği gözlendi. Yine generalize morfeası bulunan başka bir olgunun, 10 yıl öncesinde dermatomiyozit tanısı aldığı ve tedavi gördüğü öğrenildi. Morfea nedeniyle tedavi gördüğü dönemde ise dermatomiyozit ile uyumlu klinik ve laboratuvar bulgusuna rastlanmadı. Bir olguda ise vücutta morfea ve genital bölgede liken sklerozis et atrofikusun eş zamanlı ortaya çıktığı, topikal steroid kullanımı ile her iki lezyonun da tamamen gerilediği izlendi. Ayrıca tüm hastaların $\% 13,7$ 'sinde $(n=8)$ alopesi areata, liken sklerozis et atrofikus, ANCA (+) kresentik glomerülonefrit, çölyak hastalığı, hashimato tiroiditi, liken planus, psöriazis, vitiligo (Resim 1 ) gibi otoimmun hastalıklarla birliktelik saptandı.

\section{Tartışma}

Morfea, lokalize skleroderma olarak da bilinen patogenezi tam olarak anlaşılamamış, kronik seyirli, iyileşme ve alevlenmelerle seyredebilen deri ve subkutan dokuda fibrozis ile karakterli bir hastalıktır. Travma, radyasyon, ilaçlar, infeksiyonlar, otoimmünite ve mikrokimerizm gibi multifaktöryel etkenler morfea gelişimine neden olabilmektedir ${ }^{1}$. Çalışmamızda morfea etyolojisinde rol alabilecek etyolojik faktörler, demografik özellikler ve olguların tedavi yanıtları değerlendirilmiş, hastalık başlangıç yaşı, cinsiyet oranı, lezyonların morfolojik özellikleri ve hastalık süresi gibi bulguların literaturle benzerlik gösterdiği gözlenmiştir. Morfeanın kadın hastalarda 2,4 ile 4,2 kat daha sık görüldüğü bildirilmiştir7,8. Çalışmamızda kadın erkek oranı 5,4 olarak bulundu. Tüm yaş gruplarını ve sadece yetişkinleri kapsayan morfealı hastalarla yapılan çalışmalarda morfea görülme yaşı ortalama 30 ve 40 yıl olarak bulunmuştur7,9,10. Olgularımızda hastalık başlangıç yaşı literatür ile uyumlu olarak ortalama 42,33 yıl olarak belirlenmiştir.

Literatürde plak tip morfeanın en sık görülen tip olduğu yayınlanmıştır7,8. Çalışmamızda da en çok plak tipe rastlanmıştır (n:36). Çocuklarda, lineer morfeanın en sık görülen alt tip olduğu bildirilirken, az sayıda çalışmada plak tip morfeanın en sık görülen alt tip olduğu ileri sürülmüş, 
fakat lineer morfeanın yetişkinlerle karşılaştııılığında oransal olarak daha fazla görüldüğü belirtilmiştir8,9,11-14. Marzona ve ark.'Iarının 239 yetişkin ve çocuk hastada yaptığı bir çalışmada miks tip çocuklarda daha fazla görülmüş ve miks tipte relapslar ve nörolojik anormalliklerin daha fazla olduğu gösterilmiştir. Bizim çalışmamızda da 8 çocuk olgunun 7'si plak tip $1^{\prime} i$ ise miks tip morfea idi. Miks morfealı olgu ise plak ve lineer morfea lezyonlarını içermekteydi. Bu yönüyle çalışmamız Mazona ve Guevara-Guterrez ve ark.'Iarının çalışmalarıyla benzerlik göstermiştir.

Yapılan çalışmalarda miks tip olguların \%60'ında ANA pozitif olarak bulunmuştur ${ }^{12}$. Bizim çalışmamızda ise miks tip morfealı hastaların sadece $\% 8,7$ 'sinde ANA pozitifliğine rastlanmıştır. Çalışmamızda ANA pozitifliğinin daha az görülmesi hasta sayısının azlığı ile ilişkili olabilir. Morfeada otoantikor pozitifliği de çok yaygın olarak görülür. ANA, anti ds-DNA, anti-histon antikor, anti-Scl 70 gibi birçok otoantikor pozitifliği, morfealı olgularda bildirilmiştir ${ }^{1}$. Periferal eozinofilinin generalize ve lineer morfea ile ilişkili olduğu bildirilmiş, fakat halen bu otoantikorların klinik ve prognostik önemi anlaşılamamıştır ${ }^{9}$. Sato ve ark.'nın yaptığı bir çalışmada anti-histon antikorların morfea lezyonlarının sayısı ile ilişkili olduğu saptanmış ve generalize morfealı olgularda serolojik belirteç olabileceği öne sürülmüştür ${ }^{15}$. Çalışmamızda anti-histon antikor ve periferal eozinofili 1 olguda saptanmış ve literatür bilgisi ile uyumlu olarak lezyonların vücutta generalize olduğu görülmüştür.

ANA pozitifliği literatürde olguların \%7,7-\%73'ünde saptanmıştı77,8,10,12,13,16. Guevara-Gutierrez ve ark.'nın yaptığı çalışmada ANA pozitifliği (olguların \%29'u) hastalık yaygınlığı ile ilişkili bulunmuş, generalize morfeada plak morfeaya oranla ANA pozitifliğinin istatistiksel olarak anlamlı olduğu belirlenmiştir ${ }^{14}$. Leitenberger ve ark.'nın yaptığ çalışmada ANA olguların \%39,3'ünde pozitif bulunmuş, pozitiflik oranının generalize ve miks tiplerde daha yüksek olduğu bildirilmiş̧ir ${ }^{10}$. Çalışmamızda ANA pozitifliği \%26,1 olarak bulunmuş ve ANA pozitifli generalize morfealı hastalarda istatistiksel olarak anlamlı bulunmuştur. Marzano ve ark.'nın yaptığı çalışmada ANA pozitifliği erişkin morfealı olguların \%45'inde, çocukların ise \%26'sında saptanmış, hastalık aktivitesi ile ilişkili bulunmamıştır ${ }^{13}$. Çalışmamızda bir çocuk olguda ANA pozitifliği mevcuttu ve miks tip (plak+lineer) olan bu olgu metotreksata tam yanıt vermiştir. Aynı çalışmada 1 yetişkin ve 3 çocuk olguda anti-Scl 70 pozitif saptanırken, 5 yıllık takiplerde bu hastalarda sistemik skleroz gelişmediği bildirilmiştir. Çalışmamızda anti-Scl 70 bir olguda pozitif bulunurken, metotreksat ve sistemik steroid ile tedavi sonrası anti-Scl 70 negatifleştiği ve 2 yıllık takiplerde sistemik skleroz gelişimi izlenmediği görülmüştür.

Plak tip morfeada birinci basamak tedavide topikal takrolimus, 8 haftada yanıt alınamaz ise topikal imikimod, kombine kalsipotriol ve betametazon, lezyona sınırlı fototerapi (UVA1, dbUVB, UVA) bildirilmiş tedavilerdir17-19. Generalize morfeada birinci basamak tedavide metotreksat ile karşılaştırılığında yan etki profili daha az olan fototerapi (UVA1, dbUVB, UVA), tedaviye 8 haftada yanıt alınamaz ise kombine sistemik steroid ve metotreksat, bu kombinasyon ile de 8 haftada yanıt alınamaz ise mikofenolat mofetil bildirilmiş tedavi seçenekleridir20-22. Lineer morfeada ise kombine metotreksat ve sistemik steroid, 8 haftada yanıt alınmaz ise mikofenolat mofetil veya fototerapidir23.

Primer fonksiyonu mitoz sırasında mitotik iğsi cisimlerin oluşum ve fonksiyonunu inhibe eden tubuline bağlanmak olan kolşisinin fibroblast proliferasyonunu "invitro" olarak inhibe ettiği de gösterilmiştir24. Ayrıca kolşisin tedavisi alan hayvanların tunika albuginealarında daha az kollojen depozitleri oluştuğu, elastik liflerde azalma ve TGF-1 protein ekspresyonunda azalmaya neden olduğu da gösterilmiştir25. Anti- inflamatuvar ve fibroblast proliferasyonun inhibe edici etkisinden yola çıkarak çalışmamızda olguların 23 tanesine kolşisin tedavisi uygulanmıştır. Çalışmamız morfea tedavisinde kolşisinin etkinliğinin değerlendirildiği ilk çalışmadır. Olguların \%91,3'ünde kolşisin tedavisi ile yeni lezyon çıkışının önlenmesi ve kolşisinin metotreksat ile karşılaştırılığında yan etki profilinin çok daha az olması, tedavide etkili ve güvenilir bir tedavi seçeneği olabileceğini düşündürmektedir. Morfea lezyonlarının 3-5 yıl içerisinde spontan olarak gerileyeceği, bu nedenle plak tip morfeada tedavi verilmesinin gerekli olmadığına inanan araştırmacılar da vardır. Morfea hastalığının kendini sınırlayıcı ve yaşam beklentisinin normal populasyon ile benzer bir hastalık olması nedeniyle daha agresif tedaviler deformiteye neden olan morfea tiplerinde tercih edilmelidir26.

Topikal tedaviler tek başına plakların tedavisinde etkin olsalar bile hastalık aktivitesini baskılayamazlar. Bu nedenle derin, fonksiyonel bozukluğa neden olan ve ilerleyici hastalıkta tek başlarına kullanımları önerilmez ${ }^{27}$. Çalışmamızda sınırlı plak tip lezyonlara sahip 7 olgunun $\sigma^{\prime}$ sında topikal kortikosteroidlerle tedaviye komplet yanıt elde edilirken, 1 olguda parsiyel yanıt alınmıştır.

Leitenberger ve ark.'nın yaptığı bir çalışmada morfealı olguların $\% 17,6$ 'sında eşlik eden otoimmün ve romatolojik hastalık (vitiligo, psoriazis, çölyak, alopesi areata, otoimmün tiroidit, vb hastalıklar) varlığı gösterilmiştir ${ }^{10}$. Fetil ve arkadaşları büllöz pemfigoid, vitiligo ve morfea birlikteliği olan bir olgu bildirmiştir28. Bizim çalışmamızda bu oran \%13,7 olarak saptanmış, eşlik eden otoimmün hastalıklar, vitiligo, alopesi areta, psoriazis, liken sklerozis et atrofikusun, liken planus, otoimmün tiroidit, çölyak hastalığı, ANCA(+) glomerülonefrit olarak belirlenmiştir. Ceylan ve ark.'nın bildirdiğine benzer şekilde bizim çalışmamızda da morfealı bir olguda liken sklerozis et atrofikus saptanmıştır29

Sonuç olarak lokalize morfea benin bir seyir göstermekle birlikte hastalarımızda spontan gerileme eğiliminde olmamış ve plak tip sınırlı lezyonlar en sık görülen alt tip olmuştur. Generalize lezyonları olan olgularda ANA pozitifliği anlamlı fark oluşturmuştur. Literatürde etkinliği daha önce değerlendirilmeyen kolşisin tedavisi ile hastalık progresyonu durdurulmuş ve olguların yarıya yakınında tam düzelme sağlanmıştır. Çalışmamızın retrospektif yapılmış olması sınırlayıcı özelliğidir. Daha kesin verilere ulaşabilmek amacıyla çok merkezli, daha geniş katıımlı ve prospektif çalışmalara ihtiyaç vardır.

\section{Kaynaklar}

1. Fett N, Werth VP: Update on morphea: part I. Epidemiology, clinical presentation, and pathogenesis. J Am Acad Dermatol 2011;64:217-28; quiz 229-30.

2. Peterson LS, Nelson AM, Su WP, Mason T, O'Fallon WM, Gabriel SE: The epidemiology of morphea (localized scleroderma) in Olmsted County 1960 1993. J Rheumatol 1997;24:73-80.

3. Murray KJ, Laxer RM: Scleroderma in children and adolescents. Rheum Dis Clin North Am 2002;28:603-24.

4. Peterson LS, Nelson AM, Su WP: Classification of morphea (localized scleroderma). Mayo Clin Proc 1995;70:1068-76.

5. Laxer RM, Zulian F: Localized scleroderma. Curr Opin Rheumatol 2006;18:60613

6. İzol B, Sarıcaoğlu H, Başkan EB, Toka SO, Adım SB, Aydoğan K, Tunalı S: Pediyatrik morfea (lokalize skleroderma) 14 olguya ait epidemiyolojik klinik ve laboratuar bulguları. Türkderm 2011;45:132-6.

7. Christen-Zaech S, Hakim MD, Afsar FS, Paller AS: Pediatric morphea (localized scleroderma): review of 136 patients. J Am Acad Dermatol 2008;59:385-96.

8. Toledano C, Rabhi S, Kettaneh A, et al: Localized scleroderma: a series of 52 patients. Curr Opin Rheumatol 2009;20:331-6. 
9. Fett $N$, Werth VP: Update on morphea: part II. Outcome measures and treatment. J Am Acad Dermatol 2011;64:231-42; quiz 243-34.

10. Leitenberger JJ, Cayce RL, Haley RW, et al: Distinct autoimmune syndromes in morphea: a review of 245 adult and pediatric cases. Arch Dermatol 2009; 145:545-50.

11. Beltramelli M, Vercellesi P, Frasin A, Gelmetti C, Corona F: Localized severe scleroderma: a retrospective study of 26 pediatric patients. Pediatr Dermatol 2010;27:476-80.

12. Vierra $E$, Cunningham BB: Morphea and localized scleroderma in children. Semin Cutan Med Surg 1999;18:210-25.

13. Marzano AV, Menni S, Parodi A, Borghi A, Fuligni A, Fabbri P, Caputo R: Localized scleroderma in adults and children. Clinical and laboratory investigations on 239 cases. Clin Rheumatol 2003;13:171-6.

14. Guevara-Gutiérrez E, Yinh-Lao J, García-Gutiérrez P, Tlacuilo-Parra A: Frequency of antinuclear antibodies in mestizo Mexican children with morphea. Clin Rheumatol 2010;29:1055-9.

15. Sato S, Fujimoto M, Ihn H, Kikuchi K, Takehara K: Clinical characteristics associated with antihistone antibodies in patients with localized scleroderma. J Am Acad Dermatol 1994;31:567-71.

16. Alimova E, Farhi D, Plantier F, et al: Morphoea (localized scleroderma): baseline body surface involvement and antinuclear antibody may have a prognostic value. Clin Exp Dermatol 2009;34:491-2.

17. Dytoc MT, Kossintseva I, Ting PT: First case series on the use of calcipotriolbetamethasone dipropionate for morphoea. Br J Dermatol 2007;157:615-8.

18. Kroft EB, Groeneveld TJ, Seyger MM, de Jong EM: Efficacy of topical tacrolimus $0.1 \%$ in active plaque morphea: randomized, double-blind, emollientcontrolled pilot study. Am J Clin Dermatol 2009;10:181-7.
19. Kroft EB, Groeneveld TJ, Seyger MM, de Jong EM: First case series on the use of imiquimod for morphoea. Am J Clin Dermatol 2005;153:815-20.

20. Kroft EB, Creemers MC, van den Hoogen FH, Boezeman JB, de Jong EM: Effectiveness, side-effects and period of remission after treatment with methotrexate in localized scleroderma and related sclerotic skin diseases: an inception cohort study. Br J Dermatol 2009;160:1075-82.

21. Weibel L, Sampaio MC, Visentin MT, Howell KJ, Woo P, Harper Jl: Evaluation of methotrexate and corticosteroids for the treatment of localized scleroderma (morphoea) in children. Br J Dermatol 2006;155:1013-20.

22. Fitch PG, Rettig P, Burnham JM, Finkel TH, Yan AC, et al: Treatment of pediatric localized scleroderma with methotrexate. J Rheumatol 2006;33:609-14.

23. Martini G, Ramanan AV, Falcini F, Girschick H, Goldsmith DP, et al: Successful treatment of severe or methotrexate-resistant juvenile localized scleroderma with mycophenolate mofetil. Rheumatology (Oxford) 2009;48:1410-3.

24. Anderson MS, Shankey TV, Lubrano T, Mulhall JP: Inhibition of Peyronie's plaque fibroblast proliferation by biologic agents. Int J Impot Res 2000;12(Suppl 3):25-31.

25. El-Sakka Al, Bakircioglu ME, Bhatnagar RS, et al: The effects of colchicine on a Peyronie's-like condition in an animal model. J Urol 1999;161:1980-3.

26. Kreuter $A$, Altmeyer $P$, Gambichler $\mathrm{T}$ : Treatment of localized scleroderma depends on the clinical subtype. Br J Dermatol 2007;156:1363-5.

27. Zwischenberger BA, Jacobe HT: A systematic review of morphea treatments and therapeutic algorithm. J Am Acad Dermatol 2011;65:925-41.

28. Fetil E, Illknur T, Kuşku E, Lebe B, Güneş AT: Coexistence of pemfigoid, morphea and vitiligo: case report. Türkiye Klinikleri J Dermatol 2007;17:56-9.

29. Ceylan N, Gürel MS, Kiremitçi Ü, Demirkesen C: Lichen scleroatrophicus in combination with generalized morphea. Türk Patoloji Dergisi 2008;24:179-83. 